\title{
ARTÍCULOS DE INVESTIGACIÓN
}

\author{
Etnografía simétrica y espiritualidad. \\ Aproximación ontológica al laicismo*
}

\author{
Symmetrical Ethnography and Spiritually. \\ An Ontological Approach to Secularism
}

\author{
Manuela Cantón-Delgado ${ }^{1}$ \\ Universidad de Sevilla
}

\section{RESUMEN}

En estas páginas me propongo conectar los debates recientes sobre el laicismo y cierta antropología de la religión/espiritualidad involucrada en un ejercicio de participación radical, simetrización y reconocimiento ontológico de los objetos que estudia. Destrascendentalizar la religión resulta eficaz hasta donde los efectos de esa operación intelectual cancelan la agencia y realidad metodológica de los seres, energías y fuerzas con los que tratan los sujetos. Maquillar u omitir lo más excepcional o incomunicable de la experiencia etnográfica y las notas de campo para diluirlo en un discurso científicamente aceptable, un proceder tan común según Favret-Saada, resulta tanto más inquietante cuando no se comparte la premisa según la cual las epistemes, relatos y prácticas religiosas pertenecen/remiten al universo de lo irracional, lo imaginario, lo inobservable, se levantan sobre un error de percepción o un desvarío intelectual, lo que convierte la verdad en un saber independiente de los enunciados de los nativos. Este artículo, que trata de todo ello y es eminentemente teórico, sería inconcebible sin los años de trabajo de campo dedicados a las cuestiones metodológicas, epistemológicas y ontológicas implicadas en la comprensión de las religiones/espiritualidades, entendidas como política, pero también como una forma excepcional de alteridad perceptiva y sensorial.

Palabras clave: Religión; Espiritualidad; Etnografía; Ontología.

* Este texto recoge algunas formulaciones de un proyecto de investigación, actualmente en fase de borrador, sobre etnografía simétrica, así como algunas reflexiones derivadas del Proyecto trianual de Investigación Fundamental no orientada ref. CSO2010-17962, del que he sido investigadora principal (2010-2014). Dicho Proyecto de I+D llevó por título "La construcción etnopolítica del evangelismo gitano: Iglesias, federaciones y nuevos actores políticos".

${ }^{1}$ Correo electrónico: mcanton@us.es. ORCID iD: http://orcid.org/0000-0002-4617-9734 


\section{SUMMARY}

In these pages I intend to connect the recent debates on secularism and a certain anthropology of religion/spirituality involved in an exercise of radical participation, symmetry and ontological recognition of the objects it studies. Detranscendentalising religion is effective as far as the effects of this intellectual operation cancel out the agency and methodological reality of the beings, energies and forces with which subjects deal. To disguise or omit the most exceptional or incommunicable aspects of ethnographic experience and field notes, diluting them in a scientifically-acceptable discourse - a common procedure according to Favret-Saada - is all the more disturbing when one does not share the premise according to which epistemes, religious narratives and practices belong to the universe of the irrational, the imaginary, the unobservable, when they arise from an error of perception or an intellectual delusion, which turns truth into a knowledge independent of the statements of the natives. This article, which deals with all of this and is eminently theoretical, would be inconceivable without years of fieldwork dedicated to the methodological, epistemological and ontological issues involved in the understanding of religions/spiritualities, understood as politics, but also as an exceptional form of perceptual and sensory alterity.

Key words: Religion; Spirituality; Ethnography; Ontology.

If we wanted home truths, we should have stayed at home (Geertz 1984: 276).

Solo catorce años después de haber escuchado las primeras palabras de los ilongot sobre la aflicción y la ira que siente un cazador de cabezas, empecé a comprender su fuerza abrumadora (Rosaldo 1993: 3).

\section{INTRODUCCIÓN}

Más de dos décadas de investigación antropológica con religiones me han llevado a interesarme tanto por la relación entre sistemas religiosos/espirituales, política y esfera pública, como por las cuestiones metodológicas, epistemológicas y ontológicas implicadas en la etnografía con religiones/espiritualidades, entendidas como una forma excepcional de alteridad perceptiva y sensorial. Destrascendentalizar la religión me ha resultado eficaz hasta donde los efectos de esa operación intelectual cancelan, desacreditan o simplemente privan de conocer/experimentar la agencia y realidad metodológica de las entidades, energías o fuerzas con los que se relacionan rutinariamente los creyentes. Poco importa que se trate de la brujería en el Bocage francés o en Níger (Favret-Saada, Stoller), de religiones afrobrasileñas (Goldman), de buscadores espirituales de la Nueva Era y el ambiente holístico (Heelas y Woodhead 2005; Cornejo Valle 2013) o del ubicuo evangelismo pentecostal: son sistemas espirituales y prácticas en los que el vínculo entre cuerpos y espíritus se establece a través de la comunicación y/o la posesión espiritual, y cuyas etnografías están hechas de diálogos en el límite. En general confiamos en nociones (sociedad, identidad, historia o sus reversos, individuo, cultura, naturaleza, pluralismo, relativismo) que, como explica Goldman citando a Latour, se asemejan a viejos remedios que perdieron su plazo de validez: primero se volvieron inocuos y luego desencadenaron efectos negativos, deviniendo nociones que pueden haber perdido su poder para hacernos pensar. Hay quien propone no someterlas a crítica, sino abandonarlas en favor de nuevas construcciones conceptuales, máxime en una práctica -la 
etnografía - que pone a prueba las conceptualizaciones propias en el trabajo de campo y las encara con las nociones y categorías de nuestros interlocutores, cuyo punto de vista es diferente (Latour, citado en Goldman 2008: 4). Mis propios trabajos pueden haber llegado a este punto, signo de ello ha sido tentación de maquillar lo más excepcional e incomunicable de mis notas de campo para encajarlo en un relato científicamente aceptable (Favret-Saada 2005).

En este artículo trato de todo ello, proponiendo un recorrido desde lo político, los debates sobre el laicismo y las políticas de representación (inspirado en mi trabajo con evangélicos gitanos), a lo metodológico: la experiencia de los antropólogos que se involucran en un ejercicio de participación radical, simetrización (Latour 2007: 138148) y reconocimiento ontológico de los objetos con los que tratan (invocando algunos episodios entresacados de mis propias etnografías). La apertura ontológica que desplaza la epistemología, es decir, los problemas de conocimiento por el sujeto, a favor de las preocupaciones sobre la naturaleza de la realidad, la alteridad radical o la recursividad, forma parte de esta discusión (Viveiros de Castro 2002; Latour 2007; González-Abrisketa y Carro-Ripalda 2016).

\section{RAZÓN SECULAR Y EPISTEME RELIGIOSA: LAICIDAD, HERMENÉUTICA E INDIVI- DUALISMO HOLISTA}

Empezaré por los debates. Las discusiones sobre la laicidad, como forma de gobierno y como dominio conceptual, han ganado vigor en el escenario post-secular de las ciencias sociales contemporáneas. La multiculturalidad y su eventual correlato, la rápida diversificación religioso/espiritual, se han instalado en las preocupaciones de los científicos sociales y en la agenda de los gobiernos occidentales. Las religiones/ espiritualidades emergentes son a menudo juzgadas como una amenaza al ideal de laicismo y al sistema de libertades, una ecuación que puede invertirse: la aparición de instituciones específicas, observatorios ${ }^{2}$ y fundaciones, destinados a radiografiar el cambiante mapa de la pluralidad religiosa y definir su tratamiento institucional desde una perspectiva laica, no evaluativa y con la vista puesta en unas sociedades cada vez más interdependientes, tiene como objetivo velar, también, por la libertad de credo. Todos estos esfuerzos van destinados a relacionarse con la parte tratable de las religiones en aras del ideal laicista, la parte empírica, observable y registrable en el caso de los científicos sociales. Lo que excede de esa parte dócil desestabiliza nuestra lógica y subvierte los límites consensuados de la percepción. Bastaría si ese exceso intratable fuese insignificante, o no tuviese efectos reales.

El filósofo Charles Taylor se ha ocupado de esa parte tratable y pública de las religiones, invitando a los científicos sociales, especialmente a los antropólogos, a encargarse de la naturaleza concreta de la experiencia religioso/espiritual, así como a

\footnotetext{
${ }^{2}$ En el caso de España, el Observatorio Pluralismo y Convivencia se define como "una herramienta de transferencia de conocimiento para la gestión pública de la diversidad religiosa. Su objetivo principal es orientar a las administraciones públicas en la implementación de modelos de gestión ajustados a los principios constitucionales y al marco normativo que regula el ejercicio del Derecho de Libertad Religiosa en España" (<www.pluralismoyconvivencia.es $>$ ).
} 
la consistencia de esos epistemes extraños tanto a la racionalidad científica como a las demandas de una esfera pública entendida en términos habermasianos. Como teórico de la secularización, Taylor ha propuesto una concepción abierta de laicidad, convencido del papel destacado que cumplen las creencias y filosofías de vida en la identidad de las personas. De ahí que la laicidad se proponga como una noción que debería incluir el respeto a la diversidad de creencias, así como de ideologías, valores morales o ideas filosóficas tomadas como el equivalente secular de las religiones (Taylor et al. 1994; Taylor 2011). Hay quienes, por ello, lo han considerado más próximo al comunitarismo y la defensa de los bienes sociales que al liberalismo, que idealmente antepone los derechos y libertades de los individuos ${ }^{3}$ (la vieja dicotomía ha tomado fuerza en la filosofía política desde hace un par de décadas). Taylor, en un ejercicio dialógico, hermenéutico y contextualista, ha definido su posición como de individualismo holista (Taylor 1997; Gracia 2010: 199): La mente y la acción de los individuos es siempre situada, depende de lo que acontece en la dimensión colectiva de los significados, en un contexto por tanto, en los intercambios de una comunidad lingüística. Por ello el espacio público solo puede ser pensado a partir de un enfoque hermenéutico del lenguaje, ya que es la dimensión hermenéutica del lenguaje la que posibilita vínculos comunicativos y genera espacios compartidos. El lenguaje es así entendido, en el sentido wittgensteiniano (y humboldtiano) de los usos del lenguaje, como la capacidad para expresar conciencia reflexiva. Taylor se aproxima así a Wittgenstein y se distancia de Georg Herbert Mead, cuya idea del papel de la socialización y la introyección en la gestión del sí mismo es diferente de la concepción dialógica que, para Taylor, funda el carácter esencialmente no-individual del espacio común. De hecho, la distancia entre uno de los más ilustres herederos del interaccionismo simbólico de G.H. Mead, el sociólogo Erving Goffman, y el mismo Mead, reside justo en el tipo de críticas que Taylor formula a los postulados constructivistas de Mead: no se puede, afirma Goffman, partir de la situación tal y como es enunciada por el actor y hacer de esta construcción la pieza nuclear de la investigación sociológica, porque los individuos actúan como resultantes de estructuras preexistentes, situaciones o marcos, que son limitadas y que no siempre identifican. Esas estructuras preexistentes conforman rituales y están arraigadas en un orden moral, que no se renueva constantemente en esa suerte de magma relativista y desanclado del interaccionismo simbólico más ortodoxo, para el cual cada interacción parte de cero y ha de entenderse exclusivamente en relación a su propio contexto de definición ${ }^{4}$. En este

\footnotetext{
${ }^{3}$ El atomismo, supuesto filosófico promovido por la revolución científica del siglo XVII, base de filosofías como la de Hobbes o Locke y consustancial a los ideales de la modernidad, fue criticado por Alexis de Tocqueville como causa de lo que llamó individualismo y su ruptura con los lazos de los afectos (Gracia 2010: 200-201).

${ }^{4}$ Quien dejara en herencia sus ideas acerca de la construcción subjetiva del orden colectivo a discípulos como Herbert Blumer, co-fundador de la escuela de Chicago, pieza clave de la sociología constructivista y maestro del sociólogo canadiense Erving Goffman. Éste último, exponente más relevante del interaccionismo simbólico y próximo a la antropología en su uso de la metodología cualitativa, la observación participante y la inmersión propias del trabajo de campo etnográfico, ingresó en 1945 en la Universidad de Chicago y logró que su perspectiva dramatúrgica y cinematográfica sobre el universo de las interacciones cotidianas cara a cara se convirtiera en el referente imprescindible de la microsociología posterior, la antropología social y de la propia
} 
sentido, el sustrato de las metáforas de Goffman es más hermenéutico que fenomenológico, y se sitúan, a la misma manera de Taylor, en una continuidad que se desliza del holismo al individualismo (metodológico, naturalista); del orden social al individuo y viceversa (Arteaga 2010: 162).

El trasfondo hermenéutico de la filosofía de Taylor es esencial para entender sus tesis políticas sobre multiculturalidad y pluralismo religioso en la esfera pública, porque solo a través de las tramas (weberianas) intersubjetivas del significado, en la que el yo se define como un yo situado, podemos superar la disyuntiva entre atomismo (que presupone un yo desvinculado) y holismo (que parte de un yo en contexto social), y postular la síntesis que disuelve la contradicción: el individualismo holista. Esta tesis afirma la irrenunciable libertad del ciudadano, sin sacrificar por ello el bien común y la vida en comunidad. En este debate se inscribe la defensa de Taylor de las minorías religiosas, su noción políticas de reconocimiento y sus ideas sobre el laicismo y el rol de las religiones, ideas que han formado parte esencial en las recientes discusiones sobre el papel de la religión en la esfera pública ${ }^{5}$, las cuales, tomando como punto de partida la obra precursora de Jürgen Habermas Historia y crítica de la opinión pública, han reconsiderado el lugar de la religión en los debates sobre lo público (Mendieta y Vanantwerpen 2011). Es cierto que, a lo largo de la segunda mitad del siglo XX, las ciencias sociales dedicaron un interés cada vez más residual a la religión: considerada como algo ajeno a nuestra vida intelectual y política, o a nuestra experiencia cotidiana compartida, se la redujo a una dimensión irracional, excluyente y hasta coactiva de la cultura que, debido a ello, debía replegarse al ámbito privado. Por el contrario, la esfera pública habermasiana (surgida en el siglo XVIII) era presentada como su antagonista, un espacio de deliberación racional y pacífica sobre el bien común de los ciudadanos, un ámbito de argumentación crítico-racional distinto del espacio del Estado (que detenta el monopolio de la coerción), la economía o la familia, y en el que, por tanto, debe imponerse un lenguaje compartido, lo que para Habermas es tanto como decir ajeno a la episteme religiosa. La religión estaba ausente en esta primera noción habermasiana del nacimiento de la esfera pública, debido quizás a prejuicios antirreligiosos, a excesos elitistas, a un cierto impulso reificador que piensa la sociedad como un todo unificado, o a una concepción esquemática, evolucionista y al cabo profética del destino de las religiones. Tanto es así que, pese al reconocimiento unánime de una modernidad postsecular para cuyo advenimiento la secularización no ha sido condición indispensable, Habermas ha seguido insistiendo en la ruptura epistémica entre razón secular y pensamiento religioso, entre fe y conocimiento: dado que las ideas religiosas se expresan en un lenguaje infranqueable para quienes no participan de esas tradiciones concretas, solo traducidas a un "lenguaje universalmente accesible se volvería posible un reconocimiento postsecular del poder de las religiones y su incorporación a una perspectiva filosófica postmetafísica" (Habermas 2011: 24).

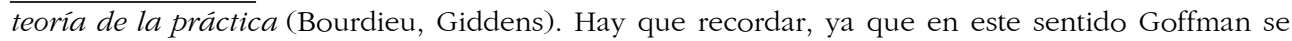
aproxima a la perspectiva de Taylor, que su interés residía en la interacción, no en la persona. Y recordar asimismo que para Blumer la acción social depende enteramente del sentido que los actores dan a sus acciones, el cual es generado intersubjetivamente en las interacciones sociales, lo que nos retrotrae en último término a la sociología comprensiva de Max Weber.

${ }^{5} \mathrm{He}$ desarrollado algunas de las consecuencias de este debate para mis propios casos etnográficos en un artículo de reciente publicación (Cantón-Delgado 2013) 
Es fácil ver que muchos pensadores parten de ese a priori reductor para decretar que en la esfera pública debemos entendernos con el único lenguaje de la razón secular: el lenguaje religioso funciona únicamente fuera del mundo secular e introduce premisas inaceptables, por irracionales, excepto para los creyentes. Ello conduce a una disyuntiva tramposa que Taylor formula así: los supuestos religiosos son "mucho más frágiles desde el punto de vista epistémico; de hecho, no te convencerán a menos que ya los admitas. Por tanto la razón religiosa o bien llega a las mismas conclusiones que la secular, y entonces es superflua, o bien llega a conclusiones contrarias, y entonces es peligrosa" (Taylor 2011: 53; Cantón-Delgado 2013). Según Taylor, Habermas acierta al defender que el lenguaje oficial de las democracias pluralistas debe evitar ciertas referencias religiosas; pero hay que evitarlas no porque sean religiosas, sino porque no son compartidas ${ }^{6}$. Para Taylor, el papel neutral del Estado secular concierne a la diversidad de ideologías, religiosas o no, por lo que el punto de vista de la religión no debería ser considerado la excepción, sino situado al mismo nivel que los puntos de vista no religiosos del mundo. El secularismo (o el laicismo) no es un asunto que enfrenta únicamente a Estado y Religión, sino que se refiere (o debería referirse) a la relación del Estado democrático con toda la diversidad (Taylor 2011: 40-54).

Para Charles Taylor la clase de renovación teórica que permitirá extender el debate y desactivar algunos de sus prejuicios implícitos debe proceder de las investigaciones socio-antropológicas y humanísticas sobre la laicidad, la coexistencia de diversos sistemas de creencias y las diferentes formas de la experiencia religiosa/espiritual (Maclure y Taylor 2011: 10). La antropología, que practica la inmersión etnográfica en otros universos de sentido, ha contribuido como ninguna otra disciplina al conocimiento descentrado y comparativo de otros epistemes. Pero generalmente ha persistido un problema de traducción, porque la tarea consiste en volver inteligibles esos universos de sentido ajenos (en grado diverso) al entendimiento científico del mundo, presentar un informe sobre ellos que satisfaga los criterios de racionalidad requeridos por la cultura a la cual pertenecen el científico y sus lectores (a menudo académicos), una cultura cuya idea de la racionalidad depende de los logros y métodos de las ciencias y que considera la magia, la consulta de oráculos o la brujería como paradigma de lo irracional (Winch 1994). De este modo el proyecto, sentido y trascendencia de esas prácticas permanecen opacos detrás de la Gran Distinción entre ellos y nosotros (FavretSaada 2005; Latour 2007: 148 y ss.; Viveiros 2002). Más allá del debate religión/espiri-

\footnotetext{
${ }^{6}$ Calhoun, en el mismo debate, se refiere en estos términos a la famosa mayoría moral del reverendo Jerry Falwell durante la época de Reagan en el gobierno de los Estados Unidos: «El peligro no está en que la Mayoría Moral fuera un movimiento conservador. Está en que quiere entrar en la arena política haciendo afirmaciones públicas basadas en verdades privadas (...). Las decisiones públicas se deben basar en argumentos que tengan un carácter público" (Calhoun 2011: 117).

7 «Las dos corrientes filosóficas mundanas más extendidas en nuestro mundo contemporáneo, el utilitarismo y el kantismo, en sus diferentes versiones, tienen puntos en los que no logran convencer a personas honestas y de mente clara. Si tomamos los enunciados clave de nuestra moralidad política actual, como los que atribuyen derechos a los seres humanos por el mero hecho de serlo, por ejemplo el derecho a la vida, no veo por qué el que seamos seres que desean/ disfrutan/sufren, o la percepción de que somos agentes racionales, habría de ser un fundamento más firme para este derecho que estar hechos a imagen y semejanza de Dios" (Taylor 2011: 58)
} 
tualidad, que en cierto sentido solo desplaza el problema ${ }^{8}$, en estas páginas examinaré algunos abordajes contemporáneos de la experiencia espiritual (religiosa o no) a través de las condiciones de posibilidad de la participación radical, el embodiment (Csordas 1993), el reconocimiento agencial de las entidades invisibles (Bubandt 2009) y los límites del enfoque puramente racionalista, epistemológico, universalista, simbolista e intelectualista de los fenómenos espirituales (Stoller 2013). Ello pasa también por discutir una cierta ontología implícita en la propia disciplina (sobre todo en la antropología anglosajona) que presupone una transparencia esencial del sujeto humano ante sí mismo. Sin embargo, basta que una experiencia etnográfica esté asentada sobre la participación radical, sobre el libre juego de la comunicación no verbal, no intencional y no voluntaria, y sobre la circulación de los afectos desprovistos de representación, para que sea posible no solo explorar la opacidad esencial del sujeto ante sí mismo (se le llame o no "inconsciente" a esa opacidad que sustenta toda la literatura terapeútica), sino situar esa opacidad en el centro mismo de nuestros análisis (FavretSaada 2005: 161) .

Tomando como punto de partida la invitación de Maclure y Taylor, trataré de aportar algunas ideas al debate teórico sobre los límites del conocimiento etnográfico; sobre el papel de la explicación racional, de la razón como "la capacidad de usar la lógica para realizar interpretaciones desapasionadas y tomar decisiones utilitarias que son un reflejo de la verdad" (Stoller 2013: 157); sobre las condiciones de la etnografía con religiones y su irrelevancia cuando cifra su esfuerzo en restablecer el orden a partir del aparente caos de un universo indescifrable (Winch 1994; Evans-Pritchard 1976); sobre la construcción de las relaciones de campo y de la interacción durante la práctica etnográfica, y el papel de los afectos, el cuerpo o los sentidos. Me serviré de mi propia experiencia en el marco concreto de la espiritualidad cristiano-pentecostal, tratando de tender el puente sugerido por Maclure y Taylor entre los debates sobre la laicidad y el manejo de la dimensión afectiva, emocional y corporal de las experiencias religiosas. Para ello utilizaré algunos conceptos-puente que desarrollo a continuación y que aplico al caso de las iglesias evangélicas gitanas, desde las políticas de reconocimiento (Taylor) al de comunidad imaginada (Anderson) y las formaciones estéticas (Meyer), para recalar, seguidamente, en la propuesta etnográfica simétrica de

\footnotetext{
${ }^{8}$ La distinción religión/espiritualidad podría ser vista como una reedición y puesta al día de la vieja dicotomía iglesia/secta, con elementos nuevos de carácter político como la institucionalización frente a la subjetivación, o la subordinación a una autoridad externa frente a la autoridad del individuo que gestiona su propia elección espiritual, y una atomización radical (Cornejo Valle 2012). Quizás de entre esos elementos el decisivo sea la convergencia entre este tipo de espiritualidad holística y la salud (Cornejo Valle 2013: 17). López-Pavillard, citando a Hufford, califica la práctica chamánica como espiritual en tanto que se ocupa del manejo de energías; según Hufford la distinción sería clara, ya que espiritualidad, en términos ottonianos, implica una "relación personal con lo trascendente", frente a religión, que definida siguiendo a Durkheim, se referiría al "aspecto comunitario e institucional de la espiritualidad" (Hufford, citado en LópezPavillard 2014: 4613). Es decir, que se trataría paradójicamente de una dicotomía nueva que nace de forzar las diferencias recurriendo a dos polos de la vieja teoría, Otto y Durkheim, que además son incompatibles entre sí.

${ }^{9}$ Favret-Saada presenta estas ideas en el transcurso de un ensayo dedicado a la antropología de las terapias y la eficacia simbólica, basado en un trabajo de campo sobre prácticas de hechicería realizado en el Bocage francés.
} 
Favret-Saada, Goldman, Stoller o Bubandt, adentrándome en algunas nociones del reciente giro ontológico por un itinerario diferente, a través de las ideas de FavretSaada, y situándolas en otros escenarios menos habituales que los conecten con la discusión tayloriana y habermasiana sobre el multiculturalismo o el laicismo, sobre la religión en general y sobre una de sus expresiones más ubicuas e impopulares: el evangelismo pentecostal. Cerraré con una coda etnográfica sobre la participación radical en el trabajo de campo con espiritualidades.

\section{DE LAS POLÍTICAS DE RECONOCIMIENTO A LAS FORMACIONES ESTÉTICAS: EL CASO DEL PENTECOSTALISMO GITANO}

En el último medio siglo el cristianismo pentecostal se ha convertido en un paradigma de la globalización religiosa y cultural (Corten y Marshall-Fratani 2001; Freston 2001; Robbins 2004). Pese a tratarse de un complejo religioso cuyos fundamentos teológicos, doctrinales, morales y rituales son generalmente muy similares ${ }^{10}$, la multiplicación de expresiones locales, sus genealogías concretas y correlatos políticos (Wilkinson y Althouse 2010: 11), y su rápida expansión transnacional, hacen que los extraordinarios episodios que tuvieron lugar en la Calle Azusa (Los Angeles, Estados Unidos) a finales del siglo XIX, y que constituyen el momento fundacional del conocido como avivamiento pentecostal, hayan dejado de resumir la historia del pentecostalismo global (Cantón-Delgado 2017).

Las poblaciones rom/gitanas tanto europeas como latinoamericanas no han quedado al margen de este seísmo espiritual y político, y si bien en Europa las identidades confesionales entre las comunidades rom permanecen aún católicas, ortodoxas, musulmanas o protestantes, la aceleración de las conversiones sugiere que los evangélicos gitanos se impondrán en términos numéricos en tan solo pocos años (Thurfjell y Marsh 2014: 7) ${ }^{11}$. En España la Iglesia Evangélica Filadelfia, denominación que aglutina a la mayoría de los evangélicos gitanos desde mediados del siglo XX, representa un movimiento religioso protagonizado por sujetos étnicos que han optado por un registro religioso y no político-cultural de sus demandas, que definen etnopolíticas desde sus propios anclajes religiosos, y que muestran una sólida voluntad de preservarse del tipo de control político, burocrático y financiero que frecuentemente revisten los procesos de reconocimiento cultural. Del mismo modo que fue una novedad histórica reivindicarse como minoría étnico-cultural ${ }^{12}$ mediante el uso político de la cultura, entendida como el principal vehículo de inserción en el orden institucional, empieza

10 Todas las expresiones del extenso complejo carismático-pentecostal comparten la intensidad emocional, corporal y extática, resultado de una fusión, afroamericana en su origen, del ascetismo puritano y el sentimentalismo metodista que marcó la evolución del cristianismo reformado en los Estados Unidos.

${ }^{11}$ Un 20\% de la población gitana española, unos 200.000 individuos de todas las edades, leen hoy la Biblia regularmente, cuentan con aproximadamente 1300 locales de culto repartidos por toda España y disponen de cuatro grandes escuelas bíblicas en las que ya se han formado más de 6000 ministros evangélicos (Cantón-Delgado 2017).

${ }^{12}$ El movimiento asociativo fue clave en este sentido de los años sesenta del siglo XX en adelante. 
ahora a ser novedad que un sector del mundo gitano se defina a través de la experiencia espiritual compartida, y no del hecho diferencial cultural. El resultado, o uno de ellos, es la aparición una noción de gitaneidad con anclaje en una espiritualidad común y en la noción de una cultura ancestral inspirada en el imaginario de la persecución y la diáspora, y coincidente con el relato bíblico.

Charles Taylor se ha referido a la necesidad de algunas etnias, insertas en los contextos multiculturales de las democracias occidentales, de asumirse como agentes activos en pos de un reconocimiento de su agencia histórica, su identidad distintiva y su papel en la arena política. Pero en el caso gitano evangélico esas políticas de reconocimiento, como Taylor las denomina, pasan por fijar su agencia en la experiencia espiritual, en la práctica ritual conjunta y en una escatología, y un relato de su pasado como pueblo, organizados en función de una teología de salvación mesiánica/ milenarista. El resultado es la noción de una gitaneidad espiritual, moral, que se desmarca de la tradición discursiva que asociaba al gitano con una raza diferente (Llera Blanes 2008: 232-235; Taylor et al. 1994). La forma en la que los grupos evangélicos manejan su pertenencia a una misma etnia y a una misma confesión religiosa de aspiraciones pangitanistas y alcance transnacional recuerda a la noción comunidades imaginadas (Anderson 1993), que Meyer prefiere denominar formaciones estéticas (Meyer 2009). Para Meyer la noción de formación presupone simultáneamente el proceso de formación de una entidad social y la entidad social misma, frente a la noción más estática de comunidad propuesta por Anderson, que invocaría un grupo social fijo y delimitado. Pero lo que aquí me interesa destacar es el uso aristotélico y no kantiano de la noción de estética, porque sitúa en primer plano la imaginación compartida manifestándose a través de la experiencia, los sentidos y las emociones. La estética es entendida como "nuestra capacidad corporal sobre la base de una potencia dada en nuestra psique para percibir objetos en el mundo a través de nuestras cinco diferentes vías sensoriales, lo que genera una constelación específica de sensaciones como un todo" (Meyer 2009: 6-9). Este énfasis en la experiencia sensorial del mundo y el conocimiento sensible sobre ese mundo se centra en el poder afectivo de imágenes, sonidos y textos sobre los sujetos, abandona la superioridad de lo simbólico y los significados sobre otros modos de experiencia, y se desmarca de la tendencia generalizada a descuidar los efectos de realidad de las formas culturales.

Todo ello apunta a un giro sensorial y hacia el cuerpo en el análisis social (Ferrándiz 2004: 22-23), que abandonaría el estudio de la imaginación en términos de representación en favor de enfoques más orgánicos y materiales de las formas culturales, más corporales, fenomenológicos en términos de Csordas, a quien el paradigma del embodiment permitió postular una concepción de la experiencia del cuerpo entendida como el punto de arranque del análisis de la participación humana en el mundo cultural (Csordas 1993: 135). Para Meyer, este movimiento hacia lo estético toma la imaginación, sobre todo en la esfera de la religión y la espiritualidad, como algo capaz de tocar a los sujetos induciéndoles un sentido de realidad inequívoco, es más: los modos en los que la imaginación se materializa y es experimentada como real impide considerarlas como meras representaciones localizadas en la mente, porque esa imaginación es literalmente incorporada y encarnada a través de experiencias compartidas, emociones y afectos que conforman un sentido común y un estilo. El estilo se sitúa así, para Meyer, en el núcleo de la estética religiosa, porque es la adopción de un estilo compartido lo 
que opera como un marcador de distinción central en los procesos de subjetivación. Todo ello también libera la propia imaginación etnográfica para adentrarse en los mundos de la religión y la espiritualidad, al dejar de enfocar exclusivamente el significado, que ha dominado el campo de la antropología de la religión, y abrirnos hacia modalidades de indagación que nos sitúan frente a dimensiones experienciales y perceptivas usualmente tratadas como secundarias. El olvido de las experiencias y la afectividad tiene la tentadora virtud de fijar y objetivar los fenómenos religiosos volviéndolos científicamente tratables, analíticamente viables, sin el riesgo de que el mundo del científico quede desestabilizado o contagiado (Favret-Saada 2005).

Si las narrativas milenaristas del evangelismo gitano/rom sobre una identidad compartida no recurren a la retórica al uso en las políticas públicas de promoción de las minorías, se debe no solamente a hartazgo político o desafección institucional, sino a que su fuente de sentido es otra: emanan de la afectividad que se origina en las experiencias colectivas de participación/interacción, en el contacto corporal y la sensualidad de los cultos, en un estilo y en una estética. No estamos tratando del cuerpo como objeto de estudio, sino de tomar el "cuerpo vivido" como dispositivo metodológico (Csordas 1993: 136). De otro modo: el reconocimiento en un discurso étnico/religioso unificador y pangitano es experimentado, en primera instancia, como el producto de una experiencia espiritual, emocional y física de (1) contacto entre creyentes, (2) contacto espiritual con entidades invisibles que tienen una indiscutible actividad en el mundo (el bautismo en el Espíritu Santo y la experiencia de los dones carismáticos) y (3) contacto con la conciencia individual (el ejercicio reflexivo de la oración en el Espíritu). Los cultos evangélicos se estructuran de hecho en torno a la comunicación no mediada de contacto entre el sujeto y el Espíritu Santo, una experiencia que funda un estilo corporal en el sentido de Meyer, y que abre paso a la participación plena en el proyecto religioso común legitimando ante el grupo su opción personal de aceptar (Llera Blanes 2008: 235). La intensa y sensorial práctica corporal carismática, el contacto continuo en los espacios del culto, la sensualidad íntima a la vez que compartida de los episodios extáticos, la posesión por el Espíritu Santo, la sanación por imposición de manos, el don que permite hablar las lenguas del Espíritu, y la liberación (de demonios), es común en todas las expresiones del pentecostalismo global, tanto europeo como, especialmente, latinoamericano y africano (Corten y MarshallFratani 2001). En parte son atribuíbles a la influencia histórica del Gospel y de las prácticas rituales afroamericanas, que formaron aquel crisol fundacional de la Calle Azusa, y las comunidades evangélicas gitanas no son la excepción a todo este universo sensorial y perceptivo.

Sirvan este caso y estas nociones como arranque de las páginas que siguen, porque es en este punto que la distancia entre el misterio de las religiones, en el caso étnicas y minoritarias, y las exigencias habermasianas del laicismo en la esfera pública se vuelve más insondable. La antropología se sitúa en ese abismo y en esa tensión, pero también ella ha tendido a aferrarse a los aspectos intelectuales de la experiencia humana y a la ficción de una ontología única (Viveiros 2002), tratando los materiales etnográficos como representaciones metafóricas de una realidad dada (Henare, Holbraad y Wastel 2007), construcciones sociales, visiones (culturales) de un mundo (natural) común, o como producto de las relaciones de poder. La tarea de rehabilitar la sensibilidad en el trabajo de campo pasa por reconocer el estatus clave 
y fundacional del encuentro etnográfico, en concreto de disposición del antropólogo a exponerse, escindirse, su apertura ante el potencial desestabilizador de lo imaginario o lo no visible, porque de ello puede depender por entero la posibilidad de adentrarse efectivamente en el mundo del otro, de comunicarse con él y, por tanto, la condición de posibilidad misma de la etnografía con religiones.

\section{SER AFECTADO: LOS LÍMITES DE LA CONSTRUCCIÓN CULTURAL Y LA REPRE- SENTACIÓN}

En su trabajo sobre la brujería en el Bocage (noroeste francés) a fines de los años sesenta, Favret-Saada ${ }^{13}$ señaló los sesgos de una antropología centrada en el análisis simbólico y el estudio representacional que, cuando reconoce el lugar de los afectos en la experiencia humana, lo hace con el propósito bien de demostrar que son meros productos de una construcción cultural y que no tienen ninguna consistencia fuera de esa construcción (versión anglosajona), o bien los desliza hacia el registro de la representación, y con ello los aboca a su propia desaparición (versión francesa y psicoanalítica) ${ }^{14}$ (Favret-Saada 1980 y 2005). Sin embargo, es precisamente la noción de "afecto" la que permite aprehender una dimensión esencial del trabajo de campo y, en su caso, repensar la antropología de las terapias: resulta revelador, señala la autora, que la eficacia terapeútica, cuando se da, resulte de un trabajo realizado sobre el afecto no representado. Para esta clase de etnografía no bastan la observación y la participación, sino que se precisa de la experimentación directa por parte del investigador, tanto como una predisposición escéptica ante las convenciones etnográficas. Favret-Saada no solo se adelantó a la crítica postmoderna al ideal objetivista, al dictado iluminista de la razón y la evidencia (Schweder, 1992), sino que incluso se atrevió a afirmar, por ejemplo, que la entrevista etnográfica formalizada es una de las modalidades más pobres de la comunicación humana. En su trabajo de campo ${ }^{15}$ Favret-

\footnotetext{
${ }^{13}$ Agradezco a Óscar Calavia el envío de este ensayo de la autora francesa y la introducción a algunos de sus trabajos.

${ }^{14}$ La autora analiza la abundante literatura etnográfica sobre brujería que encontró, dos conjuntos de textos heterogéneos que se ignoraban mutuamente: el de los folkloristas europeos, transmutados en etnólogos que no habían cambiado en absoluto su forma de trabajar, y el de los antropólogos anglosajones, sobre todo africanistas y funcionalistas. Los primeros no tenían conocimiento directo de la brujería rural sino que, siguiendo a Van Gennep, se dedicaban a investigaciones regionales contactando con las élites locales o enviando cuestionarios, o entrevistando a campesinos que informaran de si "aún se creía en esas cosas". No creían, pero siempre quedaban más allá algunos "atrasados" que sí creían... Los étnologos franceses ni observaban ni participaban. Los anglosajones que investigaban brujería practicaban la "observación participante", convertida en una especie de oxímoron: "como tomar un sorbete que hierve", es decir, combinaban dos géneros de comportamientos, uno activo, interrogando y observando a sus informantes, y otro pasivo, de observación de sucesos ligados a la brujería (disputas o consultas a adivinos). Ni el primer comportamiento puede considerarse "participación" (es en cierto modo el informante quien parece participar del trabajo del etnógrafo), ni el segundo comporta participación, salvo que entendamos que participar consiste en "estar allí", es decir: el mínimo necesario para que una observación sea posible (Favret-Saada 2005: 155-156).

${ }^{15}$ Favret-Saada publicó su primer libro en el año 1977, y llevó por título Les mots, la mort, les sorts: La sorcellerie dans le Bocage (Gallimard). El libro fue traducido al inglés en 1980 bajo el
} 
Saada se "dejó afectar" por las prácticas de brujería al punto de que fueron sus propias experiencias las que sirvieron de guía a la etnografía, a la vez que ingeniaba un dispositivo metodológico que permitiera la elaboración posterior de un cierto saber. Este dispositivo, contrariamente a lo que pudiera pensarse, excluía tanto la noción común de observación participante como la de empatía: la primera de ellas, la observación participante, limita la participación a un mero "estar allí" que posibilite la observación, que es lo único relevante. Una observación que es además parcial, porque en el caso de los estudios sobre brujería ha solido limitarse a las acusaciones, los únicos "hechos" que un etnógrafo puede "observar": "acusar" es un "comportamiento", y acaba por ser el comportamiento por excelencia de la brujería al ser el único empíricamente verificable, el resto son errores, distorsiones y productos de la imaginación nativa. Si hablar no es un acto susceptible de ser observado, y si la verdad es lo real y lo real es solo lo observable, y si lo observable además es lo empiricamente verificable, la verdad acaba por ser un saber independiente de los enunciados de los nativos, que pasan a formar parte del universo del error, de lo imaginario, lo inobservable. La palabra nativa es descualificada a favor de la palabra del etnógrafo, "cuya actividad parece consistir en hacer un desvío por Africa para verificar que son ellos (científicos) quienes detentan... la verdad" (Favret-Saada 2005: 156-157). La autora refiere cómo la literatura etnográfica manejada se limitaba a responder a una única cuestión: quién acusa a quién de ser embrujado, descuidando en cambio otros aspectos, por ejemplo cómo se entra en una crisis de brujería o cómo se sale de ella, cómo son las experiencias, las ideas y las prácticas cotidianas en ese dispositivo complejo que se extiende más allá de los rituales centrales ${ }^{16}$.

El trabajo de Favret-Saada sitúa en el centro del debate cuestiones que no son nuevas en la antropología de la religión/espiritualidad, pero que incluso en el caso excepcional de Evans-Pritchard fueron abordadas de un modo lateral, pese a reconocer que la consulta de oráculos antes de las jornadas de caza con los nativos no entraba en contradicción con sus propias creencias y pese a que, como nos recuerda Llera Blanes, el mismo Evans-Pritchard recriminara a sus colegas africanistas su incapacidad para comprender religiones no occidentales debido a sus "prejuicios ateos" (Llera Blanes 2006: 224). La de Favret-Saada fue, además, la primera etnografía que se ocupaba de registrar la existencia contemporánea de la brujería en la sociedad francesa. En los años sesenta los estudios negaban la existencia de una brujería rural en la Francia contemporánea, un error de insólitas proporciones que solo podía explicarse, según la autora, por el empeño puesto en seguir sosteniendo la "Gran División" entre ellos y nosotros, protegiendo al etnógrafo de cualquier contaminación por pertenecer al mismo mundo que su objeto, un mundo de errores intelectuales y falacias imaginarias (Latour 2007: 148). Los campesinos del Bocage sabían que esa Gran División les reservaba la peor parte,

título Deadly Words: Withcraft in the Bocage (Cambridge). El Bocage atrajo por más de cuarenta años la atención de la autora, que le dedicaría dos libros más. La autora comenzó a escribir el "Epílogo" al último de esos libros, dedicado a sus diarios de campo (Corps pour corps: enquête sur la sorcellerie dans le Bocage), en 1987 cuando fue invitada a dar una conferencia en la reunión anual de la American Anthropological Association, en Chicago. Es ese sucinto texto el que conocemos como "Être affecté", y el que analizamos aquí (Zapata y Genovesi 2013: 51-52).

${ }^{16} \mathrm{La}$ autora afirma que ni un autor tan cuidadoso como Turner se ocupó de eso, es preciso volver sobre Evans-Pritchard si buscamos respuesta a algunas de esas preguntas (Favret-Saada 2005: 156). 
la del atraso y la ignorancia, mientras la etnógrafa encarnaba el saber, de la Ciencia, la verdad, lo real, de modo que solo aceptaron hablar de brujería a condición de que la investigadora se dejase afectar por esa brujería, mostrando que tenía efectos reales sobre ella, lo que empezó a evidenciarse al aparecer las primeras reacciones fuera de su control (Favret-Saada 1980: 11-12). Fue entonces cuando acudieron a ella para pedirle un trabajo de brujería o para ayudarla a deshacer el hechizo del que habían sido víctimas, es decir: en tanto que etnógrafa, quienes se dirigían a ella para hablar de brujería se esforzaban por ridiculizar esas prácticas, repetían consignas que respondieran a las expectativas que presuponían a la investigadora; solo exponiéndose empezaron a considerarla parte de ese complejo, si bien ella jamás creyó en el poder de la brujería. Es más: la autora afirma dudar de que los mismos campesinos de su estudio crean en su poder del modo que describen usualmente los textos. Ellos querían que experimentase, no como científica, sino como persona, los efectos reales de «esa red particular de comunicación humana" en la que consiste la brujería.

La disyuntiva, un clásico del método etnográfico y de toda la tradición comprensiva, no se le escapaba: participar de esa forma no se distinguía demasiado de una "aventura personal" (lo que amenazaba su proyecto de conocimiento), pero limitarse a "observar" la dejaría sin nada relevante que decir (lo que lo arruinaba). Clifford Geertz ya había definido la etnografía como esa interacción entre el ejercicio científico y la experiencia personal (Geertz 1988: 27). Sin embargo, el método tuvo éxito: en los encuentros no se esforzaba por entender, retener, investigar, y fuera de los encuentros elaboraba una crónica de aquellos episodios enigmáticos, cuando ello era posible, porque con frecuencia la intensidad saboteaba el relato distanciado, frío. El diario de campo resultó crucial, no solo porque se convirtió en el compendio que contenía la totalidad de sus materiales de campo, sino porque mediante el diario trataba de entender (1) qué se esperaba de ella en el campo, para poder actuar en las situaciones concretas que demandaban su participación; y además (2) el diario le permitía comprender, una tarea que podía posponer pero a la que no se sentía capaz de renunciar. Ahora bien, comprender ¿para ella? ¿para la antropología? ¿para la "Conciencia europea"? No lo sabía, pero organizó el diario de campo de manera que más tarde pudiera servir a una operación de conocimiento: precisión en las notas para poder evocar con minuciosidad los episodios, y así, eventualmente, comprenderlos. El diario de campo no era un espacio íntimo y subjetivo de recreación personal y hasta literaria, a la manera de Malinowski, en absoluto un soporte libre de los encorsetamientos teatrales de la interacción en el campo: era el taller de toda aquella experiencia, a veces inenarrable, otras volcada desordenadamente tan solo para paliar la angustia.

La osadía de la autora solo es comparable a su elegante escepticismo con respecto a los convencionalismos académicos: ya hemos visto cómo Favret-Saada sostiene que su experiencia no puede ser calificada como "participación" en el sentido clásico, pero añade que tampoco debería ser entendida como una operación de conocimiento por "empatía", en ninguna de sus dos acepciones; ni en el sentido de experimentar vicariamente los sentimientos, percepciones y pensamientos de otro, ya que esa acepción presupone distancia ${ }^{17}$; ni en el sentido de empatía como comunión afectiva, ba-

\footnotetext{
${ }^{17}$ Es precisamente porque no se está en el lugar del otro que se intenta imaginar lo que sería estar allá, pero ella estaba en el lugar del nativo, imaginarlo es insuficiente o quizás hasta imposible para quien, como el etnógrafo, está habituado a trabajar con representaciones.
} 
sada en la instantaneidad de la comunicación, porque esa identificación nada nos dice sobre el mecanismo de la identificación, sino solo sobre su resultado. De hecho ser afectado, ocupar el lugar de la autora en el sistema de la brujería, nada tiene que ver con los afectos del otro sino con los propios afectos, y con la propia biografía. Este género de conocimiento inaugura una comunicación específica con los nativos, involuntaria y desprovista de intencionalidad, verbal o no.

Un caso semejante es el de Paul Stoller, quien se convirtió en un aprendiz de brujo durante su trabajo de campo en la República de Níger. El autor, que cita a FavretSaada, cuya poderosa narración ${ }^{18}$ considera una especie de teoría ecológica de la brujería semejante a las ideas de Gregory Bateson sobre la cismogénesis simétrica y complementaria, explora las dos epistemologías encargadas de la verdad: la epistemología de la "verdad de los enunciados" y la de la "verdad del ser". Para la primera la erudición es una cuestión de coherencia lógica, la verdad emerge a través del argumento lineal y lógico, tiene una larga historia y ha dado forma al discurso científico y de las ciencias sociales en los dos últimos siglos. El apasionante debate sobre la racionalidad da buena cuenta de ello: Levy-Bruhl, Evans-Pritchard, Winch, Horton, Sperber, Jarvie, Lévi-Strauss, Geertz (Cantón-Delgado 2009: 171-202), son exponentes de los diferentes enfoques centrados en la explicación racional de los fenómenos religiosos: el universalista/racionalista (para quienes defienden la existencia de una racionalidad universal los relativistas son sujetos ingenuos y poco científicos), el relativista (para quienes defienden la existencia de múltiples racionalidades los racionalistas son seres etnocéntricos e insensibles) y el fenomenológico, que se enfoca a la experiencia vivida (Stoller 2013). En cambio, la epistemología de la "verdad del ser" se adentra en las simas filosóficas de la condición humana, y se sitúa en los límites de la literatura, la filosofía, las artes y los estudios religiosos. Los antropólogos de la religión han solido confiar en la epistemología de la "verdad de los enunciados", que lleva a producir textos de una importancia efímera; solo quienes han encarado a la vez tanto las opacas cuestiones del ser como las de la estructura son capaces de producir obras que trascienden el momento en el que fueron creadas. Son las que tratan, sostiene Stoller, con cuestiones como las texturas del amor, el odio, la lealtad, la traición, la vida, la muerte, el miedo o el coraje, o la experiencia religiosa, y que son por ello capaces de acercarse a la evasiva "verdad del ser" y al conocimiento que produce. Quizás ha sido Thomas Csordas quien más se ha aproximado a este tipo de enfoque fenomenológico para rebasar el dualismo racionalismo/relativismo, probando a explorar la naturaleza de la experiencia humana a partir de la filosofía de Husserl y el método de la epoche, o reducción fenomenológica, que describe la conciencia humana en su inmediatez vivida, en ese desorden justamente anterior al momento en el que es sometida a la elaboración teórica y la sistematización conceptual. Más allá de los dilemas conceptuales de la fenomenología, cuya relevancia sociológica fue excepcionalmente abordada por Merleau-Ponty, Schütz y Garfinkel, lo cierto es que sin su contribución una antropología de la religión y la espiritualidad está incompleta: la sensualidad y la encarnación son el punto en el que se quiebra la dualidad mentecuerpo. En este sentido, Stoller postula la racionalidad encarnada como un concepto clave: la mayoría de los académicos experimentamos la encarnación, el cuerpo y

\footnotetext{
${ }^{18}$ Stoller se refiere a Deadly Words: Withcraft in the Bocage (1981).
} 
la conciencia como un espacio intelectualmente incómodo, porque contradice la epistemología de la verdad de los enunciados y su correspondiente teoría de la verdad (verdad accesible a través de una representación fiel de la realidad, capaz de reflejar lo que hay en el mundo). Stoller invoca a Rorty y a los filósofos tildados de irracionales por el stablishment filosófico, principalmente Heidegger, Wittgenstein y Dewey, quienes se apartaron de la verdad de los enunciados para acercarse a la verdad del ser, a aquello que cuesta explicar sin reducir y apenas se puede describir, y que - reconozcámoslo- forma parte de lo que la antropología de la religión/espiritualidad encara rutinariamente (Stoller 2013: 154-162).

En mi trabajo de campo con cristianos pentecostales he conocido esa inquietud ante las limitaciones de la comprensión intelectual, el recurso a la imaginación, la emoción y la experiencia estética, la creatividad, el desvío de la convención como una tentación constante, el temor de estar subestimando la intensidad de lo que presenciaba y en lo que, sin ser creyente, participaba, para hacerlo encajar en una retórica plausible. O su reverso: el temor a socavar el compromiso con la ciencia dando entrada a lo incomunicable. O peor: la prudencia para no caer en una retórica contra la ciencia ni abrir puerta alguna a la justificación de cualquier fanatismo irracional. Pero el caso es que necesitamos al menos tanta imaginación como ponen en juego los sujetos creyentes, no menos, porque la presencia de lo que se resiste a una explicación sistemática es abrumadora, como lo es la abundancia de situaciones en las que el etnógrafo es el interrogado acerca de su resistencia a creer, a la conversión y/o a la aceptación de lo inexplicable, por parte de sus interlocutores. Veamos algunos ejemplos propios.

Uno. En Orcasitas, barrio obrero del sur de Madrid, un influyente pastor gitano me contaba la historia de su vida. Llegado a un punto del relato percibí que me invitaba a participar en ella, en $s u$ historia, lo que por un lado contraviene las reglas del método, mientras por otro invita a pensar en la clase de conversación que es aquella en la que solo interviene una de las partes. Le conté un episodio de mi propia historia familiar por el que atravesaba en aquellos momentos. Me escuchó atentamente, quería saber algo más de la exótica vida de una antropóloga, y yo me he preguntado a menudo por qué lo hice. No fue para lograr un protagonismo que no buscaba y que en etnografía suele estar contraindicado, ni para ganarme unos favores que ya tenía, tampoco para encontrar consuelo ni para que solucionase un problema que, entonces como ahora, no tenía fácil solución. Lo hice por un convencimiento instantáneo, casi físico, no intencional ni consciente, de que la comunicación es intercambio, porque la situación pedía esa reciprocidad, y porque preferí reconocerlo (e incluso necesitarlo) a esforzarme en reprimirlo; lo hice porque él esperaba de mi que yo correspondiera contándole algo de mi propia vida y preferí el ejemplo de Laura Bohannan (1996) al del inspector Kurt Wallander ${ }^{19}$ quien, ante alguno de sus sospechosos/informantes, no tiene más remedio que recordarles con pesar: "aquí las preguntas las hago yo". Compartí con aquel pastor un estado de ánimo y de conciencia, al tiempo que reconocía con honestidad su autoridad en una materia que me es ajena e insondable: la cura de las almas.

${ }^{19}$ He leído casi toda la saga del inspector Kurt Wallander, protagonista de las historias urdidas por el escritor sueco de novela negra recientemente fallecido Hennig Mankell. 
Dos. Han sido incontables los interlocutores en el campo a quienes, a lo largo de dos décadas, he narrado unas conversiones muy próximas, las de mis padres, muchos años atrás; un patrimonio valiosísimo para quien está interesado en tratar con creyentes sin ser creyente. Ese relato me convertía en alguien creíble que sabía cosas de su mundo y las respetaba, alguien que, sin ser una de ellos, podía llorar y emocionarse cuando hablaban de un dios, no porque me pusiera por un instante en el lugar de ellos, sino porque era capaz de ponerme en el mío, porque sentía que eso podía pasarme, que me había pasado muy cerca, que de hecho por unos breves momentos me podría estar pasando, y que quizás más de una vez quizás debería haberme pasado. A fin de cuentas ellos se esfuerzan por demostrar vívidamente que delegar, confiar y formar parte de un plan superior en el que está todo decidido antes de la fundación del mundo es, ante todo, una experiencia liberadora. Solo una concepción cicatera tanto de la racionalidad como de la espiritualidad, solo un credo dualista a cualquier precio, que desconoce la ambigüedad y la opacidad del ser humano ante sí mismo, puede esperar del investigador que evite, silencie o maquille con distancia y discreción experiencias metodológica y biográficamente extraordinarias, para evitar el escándalo académico o la sospecha de padecer una predisposición al delirio, la sinrazón y el fanatismo. Da igual que tratemos con brujos del Bocage francés, con chamanes amazónicos o con pentecostales, o que estos sean campesinos mayas del Quiché guatemalteco o gitanos sendentarizados de un polígono urbano andaluz. Tampoco importa si se trata de servirse de la experiencia personal como categoría analítica para entender la ira que desata una pérdida devastadora, como explica Rosaldo, frente al aspecto de "receta" de tantas descripciones sobre la muerte que eliminan las emociones intensas enmascarando la fuerza emocional del luto y reduciendo el ritual funerario a "una rutina ordenada" (Rosaldo 1993: 10-13). Una ciencia que tiene como misión principal deconstruir prejuicios no debería sentirse tentada de fabricarlos, o de respaldar los existentes.

Tres. Hay otro episodio, ocurrido muchos años atrás, del que fui testigo además de protagonista, y que apenas esbocé en otro lugar (Cantón-Delgado 1998: 22-23). Dos devotas mujeres de la Iglesia Príncipe de Paz de Ciudad de Guatemala me invitaron, tras una larga conversación, a arrodillarme y tenderme en la raída moqueta de una modesta casa neopentecostal, para practicar la liberación de demonios sobre mi propio cuerpo. Me hablaron primero en susurros, en voz alta después, y comenzaron a masajearme bruscamente vientre, nuca y sienes, entonando plegarias y cánticos, llorando y hablando en lenguas, exhortando a Satanás para que abandonara mi cuerpo, buscando que vomitara los demonios. Mientras todo esto sucedía, yo temí tanto por mí como por la integridad de mi trabajo, con los ojos entreabiertos me debatía contradictoriamente, quería escapar de allí tanto como ver, por un momento, lo que ellas veían: alguien oscuro que "tejía hilos en mis pies impidiéndome aceptar". O saber si fingían. Quería saber cómo lo harían, cómo lidiarían con esas fuerzas. Era algo que no conocía, no había asistido a demasiadas sesiones de liberación, es decir: quería saber, y no luchar contra ese deseo de saber hasta sus últimas consecuencias. Deseaba comunicarme con ellas sin el temor a perder el timón de la investigación, el crédito de mis informantes o el de la comunidad académica. Y me preguntaba al mismo tiempo qué haría con todo eso, ¿registrarlo? ¿analizarlo? ¿revelarlo? No he vuelto a preocuparme de los demonios nunca más, fuera de aquella raída moqueta dejaron de 
existir. Pero aquel episodio, entre otros menos espectaculares, me mostraron que hay situaciones de campo que obligan a una cierta disociación: para comunicarse por canales inusuales con seres que no son familiares ni cotidianos (y los informantes, en general, solo lo son temporal y/o parcialmente, y con unos fines) hay que disponerse a convertir el propio ser y las propias certezas en algo que podemos extraer de dentro, depositar sobre una mano y mirar con la extrañeza de quien no tiene idea de cómo lidiar con eso. No es tanto cuestión de convertirlo en una hipótesis de trabajo ni en un juego intencional, sino de ser capaz de vivirlo seriamente, y regresar para contarlo. Y si se es capaz se producen momentos extraordinarios en el trabajo de campo: aquellos en los que no pasa nada (suele ser cuando pasa lo mejor), aquellos en los que conversamos olvidándonos de que estamos trabajando, y de que lo que sucede podría no tener sentido fuera de esas coordenadas, y, por último, esos otros en los que conseguimos olvidar quiénes somos en nuestro mundo, ése en el que nos sentimos protegidos y competentes, lo que puede ocurrir en forma de disociación y de introspección radical. Destrascendentalizar la religión y la espiritualidad sigue siendo válido, pero a cambio de que esa operación no devalúe la experiencia, quizás radical para el investigador y solo rutina para sus interlocutores, sino que la convierta en algo probable, algo que puede ocurrirnos, y que de hecho ha ocurrido alguna vez cerca de nosotros: la mayoría de los profesionales de la antropología occidental proceden de un hogar católico o protestante. Es decir, en dejar de pensarla como algo que amenaza nuestro proyecto científico, o como algo que siempre le ocurre a otros. Solo tomando en serio a demonios, entidades, fuerzas y espíritus con los que tratan quienes se relacionan con ellos podemos entrar provisionalmente en ese mundo, tratar también nosotros con ellos, en un ejercicio necesario y desestabilizador que consiste en considerarlos como fuerzas metodológicamente reales.

Favret-Saada expresa de manera precisa algo semejante a lo que viví durante la sesión de liberación en la que mis dos anfitrionas exorcistas, una vez dieron por finalizada la operación, se marcharon desafectadamente a la cocina a hablar de sus asuntos mientras yo seguía tendida en el suelo: "Cuando esa comunicación no es verbal, ¿qué es lo que se comunica y cómo?", porque no se trata tan solo de empatía pese a que sea una modalidad de comunicación inmediata, "lo que me es comunicado es solamente la intensidad con la que el otro es afectado", algo que técnicamente se asemeja a una carga energética;

no es necesario que mi experiencia sea compartida por mi acompañante: él puede, por ejemplo, estar, en apariencia, completamente desafectado (...) Supongamos que en lugar de luchar contra ese estado, lo acepto como un acto de comunicación a propósito de algo que no conozco (...) en tales casos, si soy capaz de olvidar que estoy en el campo y que tengo un arsenal de preguntas para hacer (...) entonces puedo darme cuenta que estoy lidiando con una forma particular de la experiencia humana (...) porque soy afectada por ella" (Favret-Saada 2005: 161).

Aceptar ser afectado no implica identificarse con el punto de vista nativo, ni aprovecharse de la experiencia de campo para regocijo del propio narcisismo. Supone, muy por el contrario, estar dispuesto a disolver el propio proyecto de conocimiento, porque un proyecto de conocimiento impositivo y omnipresente fulmina la posibilidad de que suceda nada relevante o de que, si sucede, seamos capaces de percibirlo. La disposición a perderse es crucial, y generalmente no se enseña en las aulas. Una premisa que 
recuerda al "buen traductor" de Talal Asad, que ante la incomprensión de un discurso extranjero mira con extrañeza su propia lengua ${ }^{20}$. Si uno se somete a una experiencia de participación radical de esta naturaleza, y no naufraga, entonces "la etnografía es aún posible". Favret-Saada sintetiza los rasgos de una etnografía de este tipo: primero, ser conscientes de que la comunicación etnográfica ordinaria (comunicación verbal, voluntaria e intencional, para aprehender un sistema de representaciones nativas) constituye una de las más pobres variedades de la comunicación humana, y es especialmente inapropiada para informarnos sobre los aspectos no verbales o involuntarios de la experiencia $^{21}$. Son, por el contrario, esas informaciones producidas en situaciones de comunicación no intencional las que detentan un estatuto epistemológico clave, las que constituyen el sustrato de la etnografía, las que nos recuerdan que hubo de único en nuestra experiencia etnográfica. Segundo, la etnografía supone vivir en un estado de escisión que permita al investigador elegir cuándo ha de dejarse moldear por la experiencia del campo y cuándo debe registrarla científicamente (si puede elegir, cabría añadir). Tercero, las operaciones de conocimiento no se superponen, porque en el momento en el que somos más afectados no podemos narrar la experiencia, en el momento en el que la narramos no podemos comprenderla, el tiempo del análisis vendrá después" (Favret-Saada 2005: 160). No coincido en este punto con la autora, más bien estoy convencida de que esos procesos mentales y afectivos son generalmente indiscernibles. Cuarto, los materiales recogidos son de una densidad particular y su análisis implica quebrar las certezas científicas establecidas ${ }^{22}$ : de no haber sido afectada, la autora habría asumido la centralidad de los rituales, no solo porque los antropólogos tienden

${ }^{20}$ "No es buen traductor quien asume que una dificultad aparente en el discurso extranjero conlleva un absurdo en ese discurso, sino quien somete a crítica su propia lengua ante tal contingencia" (Asad 1991: 226).

${ }^{21}$ Cuando un etnógrafo recuerda qué hubo de único en su estancia de campo, nos recuerda Favret-Saada, siempre habla de situaciones en las que no estaba en condiciones de practicar esa comunicación pobre, porque de algún modo estaba en manos de sus propios afectos. En las etnografías esas situaciones de comunicación involuntaria y no intencional, a pesar de ser recurrentes, no son jamás consideradas como lo que son: las "informaciones" aparecen en el texto pero desligadas de la intensidad afectiva que las acompañó, y son colocadas en el mismo plano que las otras, las que son producidas por la comunicación voluntaria o intencional. Al extremo de que podemos reconocer a un etnógrafo profesional en la medida en la que es capaz de "maquillar automáticamente todo episodio de su experiencia de campo en una comunicación voluntaria e intencional enfocada a lo aprendido de un sistema de representaciones nativas" (FavretSaada 2005: 160).

${ }^{22}$ Michael Agar desarrolló, basándose en Heidegger, el concepto de quiebra epistemológica. Situado en la tradición interpretativa y fenomenológica, Michael Agar ha postulado con Giddens que la etnografía consiste fundamentalmente en una "mediación de marcos de significado", lo que presupone la existencia de tradiciones que entran en contacto durante la etnografía y el trabajo de campo. Dado ese encuentro entre diferentes tradiciones, la etnografía debe fijar su atención en la ruptura de expectativas del observador, expectativas fijadas por su tradición, esto es, debe guiarse por el punto en el que los supuestos de coherencia saltan en pedazos (Agar 1992: 122 y ss). Para nuestro caso concreto y en un contexto de hegemonía católica de hecho, no hay que olvidar que el imaginario de la mayoría social, y una buena parte de la propia academia, asocia las manifestaciones conversionistas al fanatismo religioso, la alienación y el inmovilismo político, la pobreza estructural, el analfabetismo y la droga, en suma al tejido social de los territorios urbanos marginales. Aún revestidas de un lenguaje académico legitimador, no deja de ser un modo de no tomarlas seriamente. 
a privilegiar el análisis del simbolismo, sino porque los relatos típicos de brujería le otorgan a los rituales un lugar esencial. Debido a la exposición a discursos espontáneos, no intencionales, a las sesiones de brujería, y debido a haber experimentado personalmente todos esos episodios, los rituales acabaron por ocupar el lugar que les corresponde: uno más, el más espectacular pero no el único, aunque sea el que permite deshacer hechizos mostrando la existencia de fuerzas anormales, la crisis de los clientes afectados de hechicería y el modo cómo el hechizo es eliminado. Pero todo ello depende de un "dispositivo terapéutico" complejo que rebasa el ritual y para entender y describir el cual la observación no basta en modo alguno, sino que se precisa esta clase de participación radical (Favret-Saada 2005: 161). En mi caso entendí que el exorcismo podía ser un dispositivo de comprensión en sí mismo, que la antropología podía tomarse como una práctica de sentido en continuidad epistémica con las prácticas sobre las cuales reflexiona (Viveiros 2002: 115 y 128); que los demonios eran algo cotidiano, que deambulaban entre el salón y la cocina; y que los exorcismos podían no ser una experiencia que sucediera entre creyentes tomados por el rapto y una antropóloga fría, distante, sino algo que ocurría exactamente al revés.

\section{CODA ETNOGRÁFICA Y ONTOLÓGICA. SUBJETIVIDADES MÚLTIPLES Y ETNÓ- GRAFOS GIRADOS}

He considerado largos años que la calidad, eficacia y profundidad del trabajo de campo etnográfico giraba en torno a la noción de reflexividad (Cantón-Delgado 2008), introducida en la Antropología Social a partir del Interaccionismo Simbólico y la Etnometodología, y definida excepcionalmente por Pierre Bourdieu (Bourdieu 2003). Pero el principio de la reflexividad práctica y la retórica de la vigilancia epistemológica pueden reducirse apenas a un ejercicio solipsista y/o elitista de diálogo entre el científico y una academia que constituye su principal audiencia, mientras que el estatus metodológico de esta clase de escisión, de comunicación involuntaria, no intencional, que propone el abordaje psicoanalítico que usa Favret-Saada para redefinir el trabajo de campo, escapa a los escuetos términos de ese diálogo. Este otro enfoque de la etnografía está emparentado con la noción de quiebra epistemológica de Michael Agar, porque si bien esta concede prioridad a la visión hermenéutica de la tradición y la mediación de marcos de significado, y tiene como fin la coherencia, pasa, sin embargo, por desestabilizar las certezas y los supuestos de coherencia perfecta del investigador, en el caso de Agar rompiendo esos supuestos y siguiendo el rastro de ese desconcierto (Agar 1992). Entonces reflexividad no significaría, en términos como los que barajamos tentativamente aquí, esa recursividad que consiste en hacer una antropología de la antropología, ni tampoco consistiría en la objetivación del sujeto objetivante, tal y como postuló Bourdieu, tampoco un pretexto para la subjetivación o la reflexividad narciscista (que Bourdieu criticó), en la línea de cierta antropología crítica de los años ochenta. Se trataría más bien de una reflexividad ligada a un dialogismo radical, ni platónico ni dialéctico, que sí anticipó Pierre Clastres ${ }^{23}$ y elaboraron Marilyn

${ }^{23}$ Cuando afirmó que la etnología constituye "un discurso sobre las civilizaciones primitivas, no un diálogo con ellas" (Clastres 1968: 15). Y más: "Una diferencia considerable separa el 
Strathern y Roy Wagner (2010): es de orden etnográfico y depende de una disposición abierta a la palabra nativa que no se reduzca a narrar el relato de otros, ni a proyectarnos sobre sus conceptos, ni a suprimirlos o esclarecerlos en nuestro beneficio, ni a desmentirlos por la vía de anteponer el relato teórico a las experiencias de los otros. Consistiría más bien en decir algo diferente de los nativos sin pretender decir más de lo que dicen ellos (Goldman 2008), en simetrizar y establecer "conexiones parciales" (Strathern, citada en Goldman 2008). Puede que solo nos diferencie de los filósofos el que trabajamos con la filosofía de los otros, y solo después los articulamos con la propia (Ingold, citado en Viveiros 2002: 127). Goldman, siguiendo a Roy Wagner y a Bruno Latour, afirma que la antropología no puede rechazar la universalidad de la mediación ni reducir el significado a creencias, dogmas y certezas, teniendo entonces que elegir ( $\mathrm{y}$ creer en) entre los significados nativos y los propios. Citando Favret-Saada, sostiene que solo dejándose afectar y creando con ello situaciones de comunicación involuntaria podemos pensar en las condiciones de posibilidad del trabajo de campo. Y por último, invocando el cuarto camino de esa aún reciente antropología post-social, la filosofía de Deleuze y Guattari, Goldman se desmarca de la posibilidad de sostener cualquier relativismo que enaltezca las virtudes de las llamadas diferencias culturales. El relativismo sería otro de esos remedios que perderá su plazo de validez y se convertirá en un obstáculo para una antropología alternativa porque, nos recuerda Goldman, como afirmara Lévi-Strauss sobre el evolucionismo no pasa de ser "un intento de suprimir la diversidad de las culturas fingiendo reconocerlas plenamente». Más bien tratamos con formas de una multiplicidad intensiva, hecha de rizoma y singularidad, y la tarea principal comenzaría reconociendo la dificultad de establecer el punto exacto por donde pasan las fronteras de las culturas que difieren; que existen, mas son "sinuosas e inciertas" (Goldman 2008: 9-10).

El ensayo sobre la afectividad, que en términos de Favret-Saada es anterior a la práctica y la actividad consciente (Zapata y Genovesi 2013: 53), pese a no haberse convertido en texto canónico, ha venido inspirando el trabajo de algunos antropólogos que recogen expresamente su legado y que, en ocasiones, lo enhebran con los debates ontológicos. Es el caso, precisamente, del ensayo de etnografía simétrica de Márcio Goldman ${ }^{24}$, quien se pregunta qué ocurre si tomamos en serio a los informantes cuando nos hablan de orixás (es decir, de religión; candomblé en su caso), y dejamos de hacerlo cuando nos hablan de democracia (es decir, de política; brasileña en su caso)

etnocentrismo occidental de su homólogo "primitivo": el salvaje de cualquier tribu americana o australiana estima a su cultura superior a las demás, sin preocuparse en mantener un discurso científico sobre ellas, mientras que la etnología pretende situarse de inmediato en la esfera de la universalidad, sin darse cuenta de que en muchos sentidos permanece sólidamente instalada en su particularidad, y que su pseudodiscurso científico se degrada rápidamente en verdadera ideología". Más adelante: "La condición, en este caso, será tomar por fin en serio al hombre de las sociedades primitivas, en todos sus aspectos y en todas sus dimensiones (...). Es necesario aceptar que negación no significa la nada, y que cuando el espejo no nos devuelve nuestra imagen no significa que no haya nada para mirar" (las cursivas son del autor) (Clastres 1978:16 y 19).

${ }^{24}$ Es el caso de Márcio Goldman quien, combinando de manera novedosa las ideas de FavretSaada y las de Roy Wagner o Gilles Deleuze, defiende la posibilidad de una etnografía simétrica sobre la palabra nativa en su artículo "Os Tambores do Antropólogo: Antropología Pós-Social e Etnografía" (2008). De hecho la versión portuguesa de "Être affecté" que he manejado fue publicada en 2005 a instancias de Goldman y bajo la traducción de la antropóloga Paula Siqueira. 
en un mismo contexto etnográfico. Es probable que se deba, explica Goldman, a que estamos seguros de que los orixás no existen, de manera que nada de lo que los creyentes digan puede confrontar nuestro saber. Sin embargo sí creemos que la democracia existe. Cuando Goldman regresó a Ilhéus (sur de Bahía, Brasil) para estudiar política y no religión (candomblé), se vio confrontado a una inversión de los roles: súbitamente el antropólogo era el crédulo, y sus informantes los escépticos. Entonces, ¿qué efecto tendría esa inversión en el estudio de instituciones, valores y procesos que la sociedad a la que pertenece el antropólogo considera centrales? ¿qué ocurriría si planteáramos un experimento donde todo ocurre como si los nativos estuviesen plenamente cualificados para hablar de democracia, de manera que el antropólogo tuviese algo que aprender de ellos sobre el funcionamiento del sistema democrático en los mismos términos en los que aprendió la lógica de los orixás en el sistema del candomblé? Eso reveló que sus interlocutores eran capaces de percibir aspectos del funcionamiento de la democracia que nosotros no vemos, justamente por un exceso de compromiso. Es claro que solo una traducción de ese saber en términos académicamente aceptables podría provocar la atención de los intelectuales, pero eso no impugna la tarea central: la de simetrizar sus saberes con los saberes dominantes, lo que sitúa la propuesta de Goldman en una encrucijada de caminos entre la antropología simétrica de Bruno Latour (2007: 138 y ss.), la antropología reversa de Roy Wagner, la antropología reflexiva de Marilyn Strathern y la "filosofía de la diferencia" de Gilles Deleuze y Félix Guattari. Al tratar de lo que prefiere denominar simetrizaciones antropológicas más que antropología simétrica, Goldman plantea que el discurso de un adepto del candomblé tiende a ser considerado falso o, como mínimo, que enuncia una verdad que no es la nuestra, por lo que posee un potencial de desestabilización de nuestros modos de pensar que debe ser explorado por la antropología a través de esa especie de "comunicación involuntaria" a la que se refiere FavretSaada. La característica fundamental de la antropología sería entonces el estudio de las experiencias humanas a partir de una experiencia concreta, la del etnógrafo, que se enfrenta a la seguridad de otros en sus propios enunciados, creencias, acciones, y se pregunta hasta dónde podrá soportarlo, tomarlo en serio, y hasta dónde puede promover su propia transformación en medio de esas experiencias, lo que nada tiene que ver con estar de acuerdo con ellos ni con forzarlos a concordar con nosotros. Tomar seriamente a esos actores de prácticas, a esos teóricos con quienes dialogamos y de quienes aprendemos y a los que, hay que recordar, ya se refirió en términos análogos Harold Garfinkel hace medio siglo, sería entonces el único criterio de calidad disponible en nuestra disciplina (Goldman 2008: 6-7; Latour 2007: 152 y ss.; Viveiros 2002: 127).

Lo que un enfoque etnográfico de este tenor puede aportar al reciente debate sobre el laicismo, las diferencias entre razón secular y episteme religiosa, las políticas de reconocimiento (Taylor et al. 1994; Llera Blanes 2008), las comunidades imaginadas (Anderson 1993) y las formaciones estéticas (Meyer 2009), consiste en llevar radicalmente más allá la mediación de marcos de significados en términos de Giddens, Gadamer y Agar, es decir, de una parte ilustre de la tradición hermenéutica, y adentrarnos en la simetrización, el cuerpo y los afectos entendidos como proyecto de conocimiento. El agente social es ante todo "un ser de carne, nervio y sentidos (en el doble sentido de sensual y significado)", y "un ser que sufre"; una etnografía capaz de 
"Capturar y transmitir el sabor y el dolor de la acción, el ruido y el furor de la sociedad", que las ciencias humanas ponen en sordina "cuando no los suprimen completamente" (Wacquant 2004: 15-16), sería un ejercicio que no solo postularía el cuerpo como vector de conocimiento, también en algunos de los escenarios del revival cristiano sobre los que pesa un sonoro prejuicio académico; no solo abordaría el conocimiento del mundo espiritual desde la dimensión carnal de la existencia, sino que abriría la posibilidad de formar etnógrafos dispuestos a simetrizar tratando con ancestros, espíritus y energías como entidades metodológicamente reales, por fuera del chantaje realista y racionalista que nos impide tomar en serio lo que es real para los sujetos que estudiamos. En términos de Nils Bubandt, quien desarrolla una línea de reflexión no muy distante de la de Favret-Saada, tratar a los espíritus como metodológicamente reales tiene importantes consecuencias analíticas para nuestra comprensión de su eficacia política. En su trabajo los espíritus son invocados por razones políticas, participan en una política espiritual en la que son a la vez instrumentos y actores, por ello los relatos de los episodios de posesión llevan a Bubandt a sugerir la necesidad de tratar a los espíritus como informantes. La razón es consistente: es así como los mismos informantes los tratan cuando los consultan. Es más, estos informantes tan atípicos, los espíritus, son informantes ideales: se prestan a una aplicación ortodoxa de la entrevista y eximen al antropólogo de verificar si lo que dicen es objetivamente verdad, de manera que puede concentrarse en el contexto social al que se refiere lo narrado. A la vez Bubandt desarrolla una crítica al vínculo constante entre el concepto antropológico de informante y las ideas convencionales acerca de la subjetividad —que siguen vigentes, pese a las evidencias etnográficas de la complejidad de la subjetividad vivida-. Para ello postula que los episodios de posesión de espíritus producen una forma de subjetividad múltiple. De hecho, la posesión es una técnica aprendida en la que el médium enseña a manejar las demandas de subjetividades en competencia, las experiencias intersubjetivas de encuentros con los espíritus. Más allá: esta idea de la subjetividad múltiple es extensible a los informantes convencionales, empíricos, porque también dentro de cada uno de nosotros conviven múltiples subjetividades en competencia.

Según Maclure y Taylor la renovación teórica en el campo del pluralismo religioso y los debates sobre el laicismo dependerá en gran medida de las investigaciones socio-antropológicas y humanísticas sobre la coexistencia de diversos sistemas de creencias, así como, muy principalmente, sobre las diferentes formas de la experiencia religiosa/espiritual (Maclure y Taylor 2011: 10). Este viaje conceptual a través de la renovación metodológica que supone el ser afectado (Favret-Saada), el trato con los espíritus entendidos como entidades metodológicamente reales, la noción de simetrización (Goldman), de racionalidad encarnada (Stoller) o de subjetividades múltiples (Bubandt) en el trabajo etnográfico, enhebrado con algunas de mis propias experiencias entre evangélicos, tal vez aporte a ese impulso renovador que viene conectado a los recientes debates ontológicos. Y a tomar seriamente lo imaginario ligado a otros modos de existencia, no en tanto que meras representaciones o símbolos, sino en su calidad de agencia. 


\section{BIBLIOGRAFÍA CITADA}

Agar, Michael. 1992. "Hacia un lenguaje etnográfico", en Clifford Geertz, James Clifford y Carlos Reynoso (coord.), El surgimiento de la antropología postmoderna: 117-137. Barcelona: Gedisa.

Anderson, Benedict. 1993. Comunidades imaginadas. Buenos Aires: FCE.

Arteaga, Eguzki. 2010. "Erving Goffman: Vida y genealogía intelectual”. ISEGORÍA. Revista de Filosofía Moral y Política 42: 149-164.

Asad, Talal. 1991. "El concepto de traducción cultural en la antropología social británica", en James Clifford y George E. Marcus, Retóricas de la Antropología: 205-234. Madrid: Júcar Universidad.

Bohannan, Laura. 1996. "Shakespeare en la selva", en Honorio Velasco (comp.), Lecturas de Antropología Social y Cultural: 119-127. Madrid: UNED. Cuadernos de la UNED 119.

Bourdieu, Pierre. 2003. El oficio de científico. Ciencia de la ciencia y reflexividad. Madrid: Anagrama.

Bubandt, Nils. 2009. "Interview with an Ancestor. Spirits as Informants and the Politics of Possession in North Maluku". Ethnography 10(3): 291-361.

Calhoun, Craig. 2011. "Epílogo", en Eduardo Mendieta y Jonathan Vanantwerpen, El poder de la religión en la esfera pública: 111-124. Madrid: Trotta.

Cantón-Delgado, Manuela. 1998. Bautizados en fuego. Protestantes, discursos de conversión y politica en Guatemala. La Antigua/Vermont, USA: CIRMA/Plumsock Mesoamerican Studies.

Cantón-Delgado, Manuela. 2008. "Los confines de la impostura. Reflexiones sobre el trabajo de campo entre minorías religiosas". Revista de Dialectología y Tradiciones Populares LXIII(1): 147-172.

Cantón-Delgado, Manuela. 2009. "Religión, racionalidad y juegos del lenguaje", en La razón bechizada. Teorías antropológicas de la religión: 171-202. Barcelona: Ariel.

Cantón-Delgado, Manuela. 2013. «Etnopolíticas del evangelismo gitano y esfera pública. Transversalidad, poder, etnicidad". Política y Sociedad 50(3): 1037-1063.

Cantón-Delgado, Manuela. 2017. "Gypsy Leadership, Cohesion and Social Memory in the Evangelical Church of Philadelphia". Social Compass 64(1): 76-91. doi: 10.1177/0037768616683327

Clastres, Pierre. 1968. "Entre el silencio y el diálogo", en Claude Lévi-Strauss, Bernard Pingaud, Luc de Heusch, Lévi-Strauss: Estructuralismo y dialéctica. Buenos Aires: Paidós.

Clastres, Pierre. 1978. La sociedad contra el Estado. Barcelona: Monte Avila Eds.

Cornejo Valle, Mónica. 2012. "Religión y espiritualidad ¿dos modelos enfrentados? Trayectorias postcatólicas entre budistas Soka Gakkai", Revista Internacional de Sociología 70(2): 327-346.

Cornejo Valle, Mónica. 2013. "La convergencia de salud y espiritualidad en la sociedad postsecular. Las terapias alternativas y la constitución del ambiente holístico". Revista de Antropología Experimental 13: 11-30.

Corten, Andre y Ruth Marshall-Fratani (eds.). 2001. Between Babel and Pentecost. Transnacional Pentecostalism in Africa and Latin America. Londres: Hurst.

Csordas, Thomas J. 1993. "Somatic Modes of Attention", Cultural Anthropology 8(2): 135-156.

Evans-Pritchard, Edward E. 1976. Brujería, magia y oráculos entre los azande. Barcelona: Anagrama.

Favret-Saada, Jeanne. 1980. Deadly words. Witchcraft in the Bocage. Cambridge: Cambridge University Press.

Favret-Saada, Jeanne. 2005. "Ser afetado". Cadernos de campo 13: 155-161.

Ferrándiz, Francisco. 2004. Escenarios del cuerpo. Espiritismo y sociedad en Venezuela. Bilbao: Universidad de Deusto.

Freston, Paul. 2001. Evangelicals and Politics in Asia, Africa and Latin America. Cambridge: Cambridge University Press.

Geertz, Clifford. 1984. "Distinguished Lecture: Anti Anti-Relativism", American Anthropologist 86: $263-278$.

Geertz, Clifford. 1988. "Descripción densa. Hacia una teoría interpretativa de la cultura", en Clifford Geertz, La interpretación de las culturas. Barcelona: Gedisa.

Goldman, Marcio. 2008. "Os Tambores do Antropólogo: Antropologia Pós-Social e Etnografía". Ponto Urbe. Revista do núcleo de antropología urbana da USP 3: [s. p.]. doi: 10.4000/pontourbe.1750

González-Abrisketa, Olatz y Susana Carro-Ripalda. 2016. "La apertura ontológica de la antropología contemporánea". Revista de Dialectología y Tradiciones Populares LXXI(1): 101-128.

Gracia Calandín, Javier. 2010. "Posibilidad de un individualismo holista. Consideraciones hermenéuticas sobre el individualismo moderno desde la filosofía de Charles Taylor". ISEGORÍA. Revista de Filosofía Moral y Política 42: 199-213. 
Habermas, Jürgen. 2011. "Lo político: El sentido racional de una cuestionable herencia de la teología política", en Eduardo Mendieta y Jonathan Vanantwerpen, El poder de la religión en la esfera pública: 23-38. Madrid: Trotta.

Heelas, Paul y Linda Woodhead. 2005. The Spiritual Revolution. Why Religion is Giving Way to Spirituality. Oxford: Blackwell.

Henare, Amiria, Martin Holbraad y Sari Wastel. 2007. Thinking through Things. Theorising Artefacts Ethnographically. Nueva York: Routledge.

Latour, Bruno. 2007. Nunca fuimos modernos. Ensayo de antropología simétrica. Argentina: Siglo XXI.

Llera Blanes, Ruy. 2006. "The Atheist Anthropologist: Believers and Non-believers in Anthropological Fieldwork". Social Anthropology 14(2): 223-234.

Llera Blanes, Ruy. 2008. Os aleluias. Ciganos evangélicos e música. Lisboa: Instituto de Ciencias Sociales/Universidad de Lisboa.

López-Pavillard, Santiago. 2014. "Qué relación tiene la salud con la espiritualidad, y cómo se entiende esta relación en Occidente? Una perspectiva entre dos puntos de vista", en Agustí Andreu Tomàs, Yolanda Bodoque Puerta, Dolors Comas d'Argemir i Cendra, Joan Josep Pujadas Muñoz, Jordi Roca Girona y Montserrat Soronellas Masdeu (eds.), Periferia, fronteras y diálogos. Una lectura antropológica de los retos de la sociedad actual. Tarragona: Universitat Rovira i Virgili, pp. 4595-4622.

MacLure, Jocelyn y Charles Taylor. 2011. Laicidad y libertad de conciencia. Madrid: Alianza Editorial.

Mendieta, Eduardo y Jonathan Vanantwerpen. 2011. El poder de la religión en la esfera pública. Madrid: Trotta.

Meyer, Birgit. 2009. "From Imagined Communities to Aesthetic Formations: Religious Mediations, Sensational Forms and Styles of Binding", en Birgit Meyer (ed.), Aesthetic Formations. Media, Religion and the Senses: 1-28. Nueva York: Palgrave-Macmillan.

Robbins, Joel. 2004. "The Globalization of Pentecostal and Charismatic Christianity". Annual Review of Anthropology 33: 117-143.

Rosaldo, Renato. 1993. Culture and Truth. The Remaking of Social Analysis. Londres: Routledge.

Schweder, Richard A. 1992. "La rebelión romántica de la antropología contra el iluminismo", en Clifford Geertz, James Clifford y Carlos Reynoso (coord.), El surgimiento de la antropología postmoderna: 78-113. Barcelona: Gedisa.

Stoller, Paul. 2013. "Religion and the Truth of Being", en Janice Boddy y Michael Lambeck, A Companion to the Anthropology of Religion: 154-168. Londres: John Wiley and Sons, Inc.

Taylor, Charles. 1997. Argumentos filosóficos. Barcelona: Paidós.

Taylor, Charles. 2011. "Por qué necesitamos una revisión radical de secularismo", en Eduardo Mendieta y Jonathan Vanantwerpen, El poder de la religión en la esfera pública: 39-60. Madrid: Trotta.

Taylor, Charles, Amy Gutmann, Kwame Anthony Appiah, Jurgen Habermas, Stephen C. Rockefeller, Michael Walzer y Susan Wolf. 1994. Multiculturalism: examining the politics of recognition. Princeton: Princeton University Press.

Thurfjell, David y Adrian Marsh. 2014. Romani Pentecostalism. Gypsies and Charismatic Christianity. Fráncfort: Peter Lang.

Viveiros de Castro, Eduardo. 2002. "O nativo relativo". Maná 8 (1): 113-148.

Wacquant, Löic. 2004. Entre las cuerdas. Cuadernos de un aprendiz de boxeador. Madrid: Alianza Editorial.

Wagner, Roy. 2010. A invençâo da cultura. San Pablo: Cosac Naify.

Wilkinson, Michael y Peter F. Althouse. 2010. Like a Mighty Rushing Wind. Innovation and the Transnational Character of Pentecostalism. Boston: Brill.

Winch, Peter. 1994. Comprender una sociedad primitiva. Barcelona: Paidós.

Zapata, Laura y Mariela Genovesi. 2013. "Jeanne Favret-Saada: "Ser afectado" como medio de conocimiento en el trabajo de campo antropológico". Avá. Revista de Antropología 23: 49-67.

Fecha de recepción: 2 de abril de 2017

Fecha de aceptación: 28 de julio de 2017 